Pesq. Vet. Bras. 37(8):883-890, agosto 2017

\title{
Parâmetros ruminais e balanço de nitrogênio em bovinos alimentados com silagem da raiz de mandioca ${ }^{1}$
}

\author{
Pablo Almeida Sampaio Vieira ${ }^{2}$, José Augusto Gomes Azevêdo ${ }^{3 *}$, Fabiano Ferreira \\ da Silva ${ }^{4}$, Luiz Gustavo Ribeiro Pereira ${ }^{5}$, André Luiz Alves Neves ${ }^{5}$, Alana Batista \\ dos Santos ${ }^{6}$, Lígia Lins Souza ${ }^{6}$ e Rafael Dantas dos Santos ${ }^{5}$
}

\begin{abstract}
Vieira P.A.S., Azevêdo J.A.G., Silva F.F., Pereira L.G.R., Neves A.L.A., Santos A.B., Souza L.L. \& Santos R.D. 2017. [Ruminal parameters and nitrogen balance in fed cattle feeding with cassava root silage.] Parâmetros ruminais e balanço de nitrogênio em bovinos alimentados com silagem da raiz de mandioca. Pesquisa Veterinária Brasileira 37(8):883-890. Departamento de Ciências Agrárias e Ambientais, Universidade Estadual de Santa Cruz, Campus Soane Nazaré de Andrade, Rodovia Jorge Amado Km 16, Bairro Salobrinho, Ilhéus, BA 45662-900, Brazil. E-mail: augustog@uesc.br

The effect of inclusion of cassava root silage on ruminal parameters and nitrogenous compounds in dairy cattle was evaluated. Five cattle cannulated in the rumen and with average body weight of $389 \mathrm{~kg}$ were distributed into a Latin square $5 \times 5$, with five levels of inclusion $(0.00,3.62,7.23,10.84$ and $14.54 \%$ of the diet dry matter $)$ of cassava root silage and five periods (10 days for adaptation and five days for data collection). The nitrogen excretion in urine and feces were not affected $(\mathrm{P}>0.05)$ by inclusion of cassava root silage in the diet. The total nitrogen intake (CNT) and nitrogen balance (NB) showed an increasing quadratic and linear behavior, respectively. The lowest CNT $(142.14 \mathrm{~g} /$ day) was obtained with the inclusion of $5.82 \%$ silage cassava root. The concentration of urea (U) and urea nitrogen (UN) in plasma and urine did not change $(\mathrm{P}>0.05)$. There was a quadratic behavior $(\mathrm{P}<0.05)$ in excreta of $\mathrm{U}$ and $\mathrm{NU}$ in the urine, with minimum point of 131.13 and $61.20 \mathrm{~g} /$ day respectively, at the level of $7.27 \%$ inclusion of the cassava root silage. No interaction $(P>0.05)$ was between the levels of cassava root silage and the collection time of rumen contents for the short-chain fatty acids, $\mathrm{pH}$ and ammonia nitrogen (NH3-N). Only the $\mathrm{N}^{-\mathrm{NH}_{3}}$ protein showed quadratic behavior, according to the inclusion levels, with the minimum point $(12.62 \mathrm{mg} / 100 \mathrm{ml}$ of rumen contents) at the level of $5.98 \%$. The level of $7.23 \%$ of cassava root silage in the diet was more efficient with the use of nitrogen compounds. The diets contribute similarly to the production of short chain fatty acids, without disturbing the rumen $\mathrm{pH}$.
\end{abstract}

INDEX TERMS: Starch, sugar cane, nitrogen, rumen, cattle.

RESUMO.- Avaliou-se o efeito da inclusão da silagem da raiz de mandioca sobre os parâmetros ruminais e o balanço de compostos nitrogenados em bovinos de origem leiteira. Utilizou-se cinco animais, canulados no rúmen, não lactan-

\footnotetext{
${ }^{1}$ Recebido em 27 de outubro de 2015.

Aceito para publicação em 13 de janeiro de 2017.

Parte da tese de Doutorado do primeiro autor.

${ }^{2}$ Programa de Pós-Graduação em Zootecnia, Universidade Estadual do Sudoeste da Bahia (UESB), Rodovia BR- $415 \mathrm{Km} 3 \mathrm{~s} / \mathrm{n}$, Itapetinga, BA 45700-000, Brasil. E-mails: pablovieira1414@gmail.com

${ }^{3}$ Departamento de Ciências Agrárias e Ambientais, Universidade Estadual de Santa Cruz (UESC), Campus Soane Nazaré de Andrade, Rodovia Jorge Amado, Km 16, Bairro Salobrinho, Ilhéus, BA 45662-900, Brasil. *Autor para correspondência: augustog@uesc.br
}

tes e com peso corporal médio de $389 \mathrm{~kg}$. Os animais foram distribuídos em um quadrado latino cinco x cinco, sendo cinco dietas com níveis de inclusão $(0,00 ; 3,62 ; 7,23 ; 10,84$; e $14,54 \%$ da matéria seca da dieta) da silagem da raiz de

\footnotetext{
${ }^{4}$ Departamento de Tecnologia Rural e Animal, UESB, Rodovia BR-415 Km 3 s/n, Itapetinga, BA 45700-000, Brasil. E-mail: ffsilva@pq.cnpq.br

${ }^{5}$ Empresa Brasileira de Pesquisa Agropecuária (Embrapa), Gado de Leite, Juiz de Fora, MG 36038-330, Brasil. E-mails: luiz.gustavo@embrapa.br, andre.neves@embrapa.br, rafael.dantas@embrapa.br

${ }^{6}$ Departamento de Ciências Agrárias e Ambientais, UESC, Campus Soane Nazaré de Andrade, Rodovia Jorge Amado Km 16, Bairro Salobrinho, Ilhéus, BA 45662-900, Brasil. Bolsista de Desenvolvimento Científico Regional (DCR), nível C, CNPq e Bolsista PNPD/CAPES. E-mails: absantos@ uesc.br, ligia_lins@yahoo.com
} 
mandioca e cinco períodos. Cada período constituiu-se em 10 dias de adaptação e cinco dias para a coleta dos dados. As excreções de nitrogênio na urina e nas fezes não foram influenciadas $(P>0,05)$ pela inclusão da silagem da raiz de mandioca nas dietas. $\mathrm{O}$ consumo de nitrogênio total (CNT) e o balanço de nitrogênio (BN) apresentaram comportamento quadrático e linear crescente, respectivamente. Obteve-se o menor CNT (142,14 g/dia) no nível de inclusão de 5,82\% de silagem da raiz de mandioca. As concentrações de ureia (U) e de nitrogênio ureico (NU) na urina e no plasma não modificaram $(\mathrm{P}>0,05)$. Observou-se comportamento quadrático $(\mathrm{P}<0,05)$ nas excreções de $\mathrm{U}$ e $\mathrm{NU}$ na urina, com ponto de mínimo de 131,13 e 61,20 g/dia, respectivamente, no nível de $7,27 \%$ de inclusão da silagem da raiz de mandioca. Não houve interação $(\mathrm{P}>0,05)$ entre os níveis da silagem da raiz de mandioca e o tempo de coleta do conteúdo ruminal para os ácidos graxos de cadeia curta, o pH e o nitrogênio amoniacal $\left(\mathrm{N}-\mathrm{NH}_{3}\right)$. Apenas o teor de $\mathrm{N}-\mathrm{NH}_{3}$ apresentou comportamento quadrático, em função dos níveis de inclusão, obtendo-se o ponto mínimo $(12,62 \mathrm{mg} / 100 \mathrm{~mL}$ de conteúdo ruminal) no nível de 5,98\%. 0 nível de 7,23\% de silagem da raiz de mandioca na dieta foi mais eficiente na utilização dos compostos nitrogenados. As dietas contribuem de forma semelhante para a produção dos ácidos graxos de cadeia curta, sem interferir no $\mathrm{pH}$ ruminal.

TERMOS DE INDEXAÇÃO: Amido, cana-de-açúcar, nitrogênio, rúmen, bovino.

\section{INTRODUÇÃO}

Dentre as opções para a alimentação animal, o milho tem sido utilizado como principal fonte de amido. Entretanto, como tem o seu preço atrelado ao mercado internacional, torna-se, em alguns momentos, desfavorável ao custo/benefício do sistema de produção, sendo necessário o uso de alimentos alternativos, que possam proporcionar melhor rentabilidade na produção de ruminantes.

Em 2011, a produção mundial de mandioca aproximou-se a 262 milhões (mi) de toneladas ( $\mathrm{t}$ ), havendo uma previsão de 291 mi de t para 2014 (FAO 2014), o que levou o Brasil a se destacar entre os principais produtores mundiais (25,4 mi de t), ficando atrás, apenas, da Nigéria $(52,4$ mi de t). Muitas vezes, o excesso de produção de raízes de mandioca resulta em menor preço do produto, criando, assim, boas perspectivas para o seu uso na alimentação de ruminantes. A raiz da mandioca integral pode ser fornecida aos animais na forma desidratada, como raspa ou farelo, ou na forma de silagem.

A digestibilidade ruminal do amido da mandioca é maior em relação ao milho, 91 e 65\%, respectivamente (Simas et al. 2008). Este fato se deve à inexistência de pericarpo, endosperma córneo e periférico, da matriz proteica e, possivelmente, por causa de uma menor proporção de amilose e de lipídios nos grânulos de amido, o que faz diminuir a quantidade de pontes de hidrogênio na molécula de amido e aumentar a capacidade de expansão do amido em meio aquoso (Rangel et al. 2008).

No rúmen, o amido é convertido em ácidos graxos de cadeia curta (AGCC), gás carbônico, amônia, metano e cé- lulas microbianas, como produtos finais da fermentação pelos microrganismos. Os ácidos graxos de cadeia curta, principalmente o acetato, o propionato e o butirato, são importantes fontes de energia para os ruminantes (Argov-Argaman et al. 2012). À proporção que são produzidos variam de acordo com a fonte de amido, sendo que a capacidade de absorção ruminal é afetada pelo potencial hidrogeniônico do rúmen.

A absorção, por meio da parede do rúmen, é o principal destino da amônia que não foi utilizada pelos microrganismos. Esse composto é retirado da circulação sanguínea pelo fígado e excretada na urina na forma de ureia (Oliveira et al. 2007). A determinação da concentração plasmática de ureia é de grande importância para evitar perdas de proteína, já que esse nutriente é responsável pela maior parte do custo financeiro na formulação de ração, além de representar custo energético para o animal (Mendonça et al. 2004).

A concentração de nitrogênio ureico no plasma e/ou no leite pode ser utilizada para monitorar a utilização do nitrogênio da dieta, evitando perdas econômicas, produtivas, reprodutivas e ambientais (Broderick \& Clayton 1997). 0 balanço de compostos nitrogenados não foi influenciado significativamente quando o milho foi substituído pela raiz de mandioca seca e triturada (0, 25, 5075 e 100\%) no concentrado para vacas leiteiras (Silva et al. 2014). Entretanto, estudos envolvendo a silagem da raiz de mandioca na alimentação de bovinos são escassos.

Realizou-se este estudo, com o objetivo de avaliar o efeito da inclusão de silagem da raiz da mandioca sobre os parâmetros ruminais, o balanço de compostos nitrogenados e as concentrações de ureia e de nitrogênio ureico na urina e no plasma de bovinos.

\section{MATERIAL E MÉTODOS}

Esta pesquisa foi conduzida em estreita conformidade com a legislação brasileira sobre as pesquisas com o uso de animais e foi aprovado pela Comissão de Ética no Uso de Animais, da Universidade Estadual de Santa Cruz, localizada em Ilhéus, Bahia, Brasil.

Conduziu-se o experimento na Fazenda Paulistinha, Macarani-Ba, situada a $324 \mathrm{~m}$ acima no nível do mar, latitude $-15^{\circ} 34^{\prime}$ $06^{\prime \prime}$ e longitude $-40^{\circ} 25^{\prime} 23^{\prime \prime}$. Foram utilizados cinco bovinos de origem leiteira, canulados no rúmen. Antes do início do experimento os animais pastejavam áreas com a Brachiaria brizantha cv. Marandu.

0 estudo foi desenvolvido em sistema de confinamento com baias individuais, com 3,0 m de comprimento e 1,8 m de largura, cobertas, providas de comedouros e bebedouros. Os animais foram distribuídos em um quadrado latino de cinco por cinco (5x5), sendo cinco dietas experimentais e cinco períodos de 15 dias cada, com 10 dias de adaptação e cinco dias para a coleta dos dados. As dietas consistiram em cinco níveis de inclusão $(0,00 ; 3,62$; 7,$23 ; 10,84$; e $14,54 \%$ da matéria seca da dieta) da silagem da raiz de mandioca, sendo que no nível de $14,54 \%$ o milho foi retirado totalmente da dieta. Foram formuladas de acordo com o Nacional Research Council (2001). 0 volumoso utilizado foi à cana-de-açúcar (Saccharum officinarum), tratada com 1\% da mistura ureia + sulfato de amônio (10:1), com base na matéria natural (Quadro 1 e 2). Antes do início do experimento, os animais passaram por um período de adaptação de cinco dias, recebendo cana-de-açúcar tratada com $0,5 \%$ da mistura ureia + sulfato de amônio (10:1), com base na matéria natural. 
A cana-de-açúcar era colhida diariamente e picada com pontas em máquina forrageira no momento do fornecimento. Durante os cinco dias do período de coleta, os teores de açúcares solúveis (ํBRIX) eram aferidos (Quadro 2) pela manhã e pela tarde, momento em que se fornecia a ração aos animais.

A silagem da raiz de mandioca foi confeccionada na própria fazenda, próximo às baias. As raízes foram picadas e armazenadas em dois silos do tipo cincho. 0 primeiro silo foi aberto 34 dias após o fechamento e o outro ao decorrer do experimento, quando acabou a silagem do primeiro silo. Todos os dias pela manhã o silo era aberto para a retirada da silagem que seria fornecida pela manhã e pela tarde.

A mistura entre o volumoso, a silagem da raiz de mandioca e o concentrado foram realizados no momento do fornecimento da alimentação, pela manhã, às sete horas, e pela tarde, às 16 horas. As dietas foram oferecidas, à vontade, de forma a permitir sobras entre 5 e $10 \%$ do ofertado.

Durante o período de coleta, amostras diárias do concentrado, da silagem da raiz da mandioca, da cana+ureia e das sobras alimentares de cada animal foram coletadas e congeladas. Posteriormente, foram desidratadas em estufa de ventilação forçada, por $72 \mathrm{~h}$, a $55^{\circ} \mathrm{C}$ e trituradas em peneira de $1 \mathrm{~mm}$ em moinho do tipo Thomas-Willey.

No Laboratório de Nutrição Animal da Universidade Estadual de Santa Cruz, Ilhéus-Ba, foram realizadas as análises de

\section{Quadro 1. Proporções de ingredientes com base na} matéria seca

\begin{tabular}{lccccc}
\hline Alimentos* & \multicolumn{5}{c}{ Níveis da silagem da raiz da mandioca } \\
\hline & 0,00 & 3,62 & 7,23 & 10,84 & 14,54 \\
Cana+ureia & 74,54 & 73,75 & 72,91 & 72,11 & 71,38 \\
Farelo de milho & 16,01 & 12,70 & 9,42 & 6,14 & 0,00 \\
Farelo de soja & 7,74 & 8,24 & 8,76 & 9,25 & 11,44 \\
Silagem raiz mandioca & 0,00 & 3,62 & 7,23 & 10,84 & 14,54 \\
Núcleo mineral & 1,08 & 1,08 & 1,08 & 1,07 & 1,05 \\
Fosfato bicálcico & 0,35 & 0,37 & 0,38 & 0,39 & 1,31 \\
Calcário calcítico & 0,27 & 0,25 & 0,23 & 0,20 & 0,28
\end{tabular}

* Cálcio 15,5\%, Enxofre 1,9\%, Fósforo 9,0\%, Magnésio 1,5\%, Sódio 11,8\%, Cobalto 85ppm, Cobre 1450ppm, Ferro 1560ppm, Fluor (máximo), $900 \mathrm{ppm}$, Iodo $95 \mathrm{ppm}$, Manganês $1825 \mathrm{ppm}$, Selêncio $24 \mathrm{ppm}$, Zinco $6230 \mathrm{ppm}$.

\section{Quadro 2. Composição químico-bromatológica da cana+ureia, da silagem da raiz da mandioca e das dietas experimentais, com base na matéria seca (MS)}

\begin{tabular}{|c|c|c|c|c|c|c|c|}
\hline \multirow[t]{2}{*}{ Itens } & \multirow[t]{2}{*}{ Cana+ureia } & \multirow{2}{*}{$\begin{array}{c}\text { Silagem } \\
\text { da raiz de } \\
\text { mandioca }\end{array}$} & \multicolumn{5}{|c|}{$\begin{array}{c}\text { Níveis da silagem da raiz } \\
\text { da mandioca }\end{array}$} \\
\hline & & & 0,00 & 3,62 & 7,23 & 10,84 & 14,54 \\
\hline MS* & 28,40 & 43,21 & 43,15 & 41,93 & 41,07 & 39,97 & 38,93 \\
\hline MO & 8 & 97,45 & 94,66 & 94,70 & 94,71 & 94,48 & 93,85 \\
\hline PB & 11,19 & 3,19 & 13,43 & 13,37 & 13,21 & 13,32 & 14,01 \\
\hline $\mathrm{EE}$ & 2,11 & 3,17 & 2,87 & 2,74 & 2,85 & 2,76 & 2,52 \\
\hline $\mathrm{CHO}$ & 82,48 & 91,09 & 78,36 & 78,59 & 78,65 & 78,39 & 77,31 \\
\hline $\mathrm{FDN}_{\mathrm{cp}}$ & 53,28 & 8,79 & 43,04 & 42,76 & 41,81 & 41,71 & 41,08 \\
\hline CNF & 29,20 & 82,30 & 35,32 & 35,83 & 36,84 & 36,69 & 36,24 \\
\hline $\mathrm{FDA}_{\mathrm{cp}}$ & 29,42 & 2,16 & 23,22 & 22,63 & 22,27 & 22,30 & 21,97 \\
\hline NDT $^{\text {cp }}$ & - & - & 60,09 & 63,74 & 61,60 & 61,71 & 60,98 \\
\hline Lignina & 5,91 & 2,01 & 4,90 & 4,89 & 4,95 & 5,00 & 4,59 \\
\hline${ }^{\circ}$ BRIX & 20,38 & - & - & - & - & - & - \\
\hline
\end{tabular}

* Matéria Natural. MO = matéria orgânica, $\mathrm{PB}$ = proteína bruta, $\mathrm{EE}$ = extrato etéreo, $\mathrm{CHO}=$ carboidratos totais, $\mathrm{FDN}_{\mathrm{cp}}=$ fibra em detergente neutro corrigida para cinzas e proteína, $\mathrm{CNF}=$ carboidratos não fibrosos, $\mathrm{FDA}_{\mathrm{cp}}$ = fibra em detergente ácido corrigida para cinzas e proteína, NDT = nutrientes digestíveis totais, ${ }^{\circ} \mathrm{BRIX}=$ teor de sólidos solúveis. matéria seca (MS) (INCT-CA G-003/1), matéria mineral (MM) (INCT-CA M-001/1), proteína bruta (PB) (INCT-CA N-001/1), extrato etéreo (EE) (INCT-CA G-004/1), fibra em detergente neutro (FDN) (INCT-CA F-002/1) e suas correções para cinzas (INCT-CA M-002/1) e proteína (INCT-CA N-004/1), obtendo-se a FDN $_{\mathrm{cp}}$, fibra em detergente ácido (FDA) (INCT-CA F-004/1) e suas correções para cinzas (INCT-CA M-003/1) e proteína (INCT-CA M-005/1), obtendo-se a FDA ${ }_{\text {cp }}$ e lignina (INCT-CA F-005/1), conforme descritos por Detmann et al. (2012).

Para estimativa dos carboidratos totais (CHO) foi utilizada a equação: $\mathrm{CHO} \%=100-(\mathrm{PB} \%+\mathrm{EE} \%+\mathrm{MM} \%)$ (Sniffen et al. 1992). Para a obtenção dos carboidratos não fibrosos (CNF), adotou-se a equação: $\mathrm{CNF} \%=100-[(\mathrm{PB} \%-\mathrm{PB} \%$ da ureia $+\%$ de ureia) + FDNcp\% + EE\% + MM\%] (Hall \& Akinyode 2000). Os nutrientes digestíveis totais (NDT) foram calculados de acordo com Weiss (1999), mas utilizando-se a FDN corrigida para cinzas e proteína, conforme a equação: NDT\% = PBD $\%$ + CNFD $\%$ + FDN${ }_{\text {cp }} \mathrm{D} \%+2,25 *$ EED\%, em que, PBD = PB digestível; CNFD = CNF digestível; $\mathrm{FDN}_{\mathrm{cp}} \mathrm{D}=\mathrm{FDN}_{\mathrm{cp}}$ digestível; EED = EE digestível.

Em um dia, dentro de cada período de coleta, foram realizadas coletas de urina, spot, em micção espontânea dos animais, aproximadamente 4 horas após o fornecimento da alimentação matutina. As amostras foram filtradas em gaze, e uma alíquota de 10 $\mathrm{mL}$ foi separada e diluída em $40 \mathrm{~mL}$ de ácido sulfúrico $(0,036 \mathrm{~N})$ (Valadares et al. 1999), sendo, posteriormente, destinada à quantificação das concentrações urinárias de ureia, nitrogênio total e creatinina. 0 teor de nitrogênio total foi estimado pelo método de Kjeldhal, conforme metodologia descrita por Detmann et al. (2012) (INCT-CA N-001/1).

A coleta de sangue foi realizada uma vez por período, aproximadamente 4 horas após o fornecimento da alimentação da manhã, utilizando-se tubos (Vacutainer) com EDTA. Em seguida, as amostras de sangue foram centrifugadas a $3.500 \mathrm{rpm}$, durante 10 minutos, e o plasma, acondicionado em microtubos (Eppendorf) e mantido congelado $\left(-20^{\circ} \mathrm{C}\right)$ até a realização das análises.

As concentrações de creatinina na urina e de ureia na urina e no plasma foram estimadas utilizando-se kits comerciais (Bioclin). A conversão dos valores de ureia em nitrogênio ureico foi realizada multiplicando-se os valores obtidos pelo fator 0,4667 .

0 balanço de nitrogênio (BN) foi calculado de acordo com a equação:

CNT (g/dia) - [ENF (g/dia) + ENU (g/dia)]; em que, CNT= consumo de nitrogênio total; ENF= excreção de nitrogênio fecal; e ENU= excreção de nitrogênio urinário.

Uma vez por período, avaliaram-se os parâmetros de fermentação ruminal: potencial hidrogeniônico $(\mathrm{pH})$, concentração de nitrogênio amoniacal $\left(\mathrm{N}-\mathrm{NH}_{3}\right)$ e de ácidos graxos de cadeia curta (AGCC). Para a obtenção do pH e das concentrações dos AGCC e do $\mathrm{N}-\mathrm{NH}_{3}$ foi coletado conteúdo ruminal. As coletas ocorreram nos tempos 0, 2, 4, 6 e 8 horas após a alimentação matinal. A leitura de $\mathrm{pH}$ foi feita através de um potenciômetro digital. Duas amostras do conteúdo ruminal foram filtradas em gaze, armazenadas e congeladas; a primeira alíquota $(10 \mathrm{~mL})$ foi utilizada para as análises de AGCC, sendo adicionado um $\mathrm{mL}$ de solução de ácido metafosfórico a $20 \%$; a segunda alíquota $(50 \mathrm{~mL})$ foi acidificada com uma solução de ácido clorídrico, a 50\%, para posterior estimativa do $\mathrm{N}-\mathrm{NH}_{3}$. A concentração de N-NH3 foi determinada por destilação com hidróxido de potássio $2 \mathrm{~N}$, de acordo com o método descrito por Fenner \& Ratcliffe (1965), adaptado por Vieira (1980).

Para a obtenção dos AGCC foi utilizado o equipamento Waters 2695, com Detector PAD 2998 (photodiode array detector), com sistema de separação constituído de pré-coluna e coluna de fase

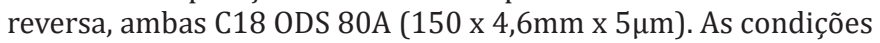
de análise foram: fase móvel com mistura isocrática constituída de $90 \%$ de solução aquosa ácida pH 2,35-2,55 e 10\% de metanol, 
temperatura do forno de $30^{\circ} \mathrm{C}$, volume de injeção de amostra de 20 microlitros, corrida com 12 minutos e detector com comprimento de onda de excitação em $210 \mathrm{~nm}$. A quantificação foi obtida por curva de calibração com uso de padrões externos.

Os dados foram analisados utilizando procedimento para delineamentos em Quadrado Latino.

O modelo matemático foi: $\mathrm{Y}_{\mathrm{ijk}}=\mathrm{m}+\mathrm{A}_{\mathrm{i}}+\mathrm{P}_{\mathrm{j}}+\mathrm{C}_{\mathrm{k}}+\mathrm{e}_{\mathrm{ijk}}$, em que:

$\mathrm{Y}_{\mathrm{ijk}}=$ observação do efeito do tratamento $\mathrm{k}$, no período j, no animal i;

$\mathrm{m}=$ média geral;

$A_{i}=$ efeito do animal $\mathrm{i}$;

$\mathrm{P}_{\mathrm{j}}=$ efeito do período $\mathrm{j}$;

$\mathrm{C}_{\mathrm{k}}=$ efeito do tratamento $\mathrm{k}$;

$\mathrm{e}_{\mathrm{ijk}}=$ erro aleatório associado a cada observação.

Em todos os procedimentos estatísticos adotou-se o nível de 0,05 de probabilidade para o erro do tipo I. Quando significativo, foi realizada a análise de regressão. Os dados de pH, N-NH3 e AGCC foram dispostos em esquema de parcelas subdivididas, com os tempos de amostragem nas subparcelas.

\section{RESULTADOS}

O consumo de nitrogênio total (CNT) e o balanço de nitrogênio (BN) foram significativamente influenciados pela inclusão da silagem da raiz de mandioca nas dietas (Quadro 3), ao contrário das excreções de nitrogênio na urina e nas fezes $(\mathrm{P}>0,05)$. Através da equação, com comportamento quadrático, obtida para o CNT, pode-se estimar o ponto mínimo para essa variável (142,14 g/dia) no nível de inclusão de 5,82\% de silagem da raiz de mandioca na dieta, enquanto o BN teve um comportamento linear crescente, à medida que foi adicionada silagem da raiz de mandioca na alimentação dos animais.

As concentrações de ureia e nitrogênio ureico na urina e no plasma não sofreram alterações $(\mathrm{P}>0,05)$ com a inclusão da silagem da raiz de mandioca (Quadro 4).

Observou-se comportamento quadrático $(\mathrm{P}<0,05)$ nas excreções de ureia e de nitrogênio ureico na urina, com ponto de mínimo de 131,13 e 61,20 g/dia, respectivamente, no nível de 7,27\% de inclusão da silagem da raiz de mandioca (Quadro 4).

Não foi verificada interação $(\mathrm{P}>0,05)$ entre os níveis da silagem da raiz de mandioca e o tempo de coleta do conteúdo ruminal para nenhum dos itens avaliados (Quadro 5).

Quadro 3. Consumo de nitrogênio total, excreções de nitrogênio na urina e nas fezes e balanço de nitrogênio de animais fistulados no rúmen, alimentados em função dos níveis da silagem da raiz da mandioca na dieta

\begin{tabular}{|c|c|c|c|c|c|c|c|c|}
\hline \multirow[t]{2}{*}{ Itens } & \multicolumn{5}{|c|}{ Níveis da silagem da raiz da mandioca (\%) } & \multirow[t]{2}{*}{ Equação } & \multirow[t]{2}{*}{$\mathrm{R}^{2}$} & \multirow[t]{2}{*}{ EPM } \\
\hline & 0,00 & 3,62 & 7,23 & 10,84 & 14,54 & & & \\
\hline $\mathrm{CMS}^{1}$ & 1,77 & 1,71 & 1,77 & 1,72 & 1,88 & $\hat{Y}=1,77$ & - & 0,09 \\
\hline $\mathrm{CNT}^{2}$ & 153,50 & 138,63 & 144,88 & 150,98 & 161,78 & A & 87,74 & 5,46 \\
\hline $\mathrm{ENU}^{2}$ & 26,40 & 20,00 & 20,65 & 20,25 & 25,00 & $\hat{Y}=22,45$ & - & 1,09 \\
\hline $\mathrm{ENF}^{2}$ & 45,55 & 37,40 & 40,78 & 45,23 & 43,03 & $\hat{\mathrm{Y}}=42,40$ & - & 2,05 \\
\hline $\mathrm{BN}^{2}$ & 81,60 & 81,28 & 83,43 & 85,48 & 93,75 & B & 77,98 & 4,45 \\
\hline
\end{tabular}

CMS = consumo de matéria seca, $\mathrm{CNT}=$ consumo de nitrogênio (N) total, ENU = excreção de $\mathrm{N}$ na urina, $\mathrm{ENF}=$ excreção de $\mathrm{N}$ nas fezes, $\mathrm{BN}=$ balanço de N; ${ }^{1} \%$ do peso corporal, ${ }^{2}$ g/dia; A $\hat{Y}=0,275 X^{2}-3,1987 \mathrm{X}+$ 151,4434, B $\hat{Y}=0,787 X+79,4027 ; R^{2}=$ coeficiente de determinação, $\mathrm{EPM}=$ Erro padrão da média.
Quadro 4. Concentrações de ureia e nitrogênio ureico na urina e no plasma, e excreções de ureia e nitrogênio ureico na urina de animais, fistulados no rúmen, alimentados em função dos níveis da silagem da raiz da mandioca na dieta

\begin{tabular}{|c|c|c|c|c|c|c|c|c|}
\hline \multirow[t]{2}{*}{ Itens } & \multicolumn{5}{|c|}{ Níveis da silagem da raiz da mandioca (\%) } & \multirow[t]{2}{*}{ Equação } & \multirow{2}{*}{\multicolumn{2}{|c|}{$\mathrm{R}^{2} \quad \mathrm{EPM}$}} \\
\hline & 0,00 & 3,62 & 7,23 & 10,84 & 14,54 & & & \\
\hline \multicolumn{9}{|c|}{ Concentrações (mg/dL) } \\
\hline UU & 1646,42 & 1689,84 & 1458,16 & 992,65 & 1506,57 & $\hat{Y}=1$ & 3 & 157,03 \\
\hline NUU & 768,39 & 788,65 & 680,53 & 463,27 & 703,12 & $\hat{Y}=680,79$ & - & 73,29 \\
\hline UP & 27,51 & 32,06 & 32,53 & 31,94 & 33,10 & $\hat{Y}=31,43$ & - & 1,91 \\
\hline NUP & 12,84 & 14,96 & 15,18 & 14,91 & 15,45 & $\hat{Y}=14,67$ & - & 0,89 \\
\hline \multicolumn{9}{|c|}{ Excreções (g/dia) } \\
\hline UU & 179,3 & 127,71 & 14 & 136,34 & 172 & 7 & 77 & 8,98 \\
\hline NUU & 83,71 & 59,6 & 68,1 & 63,63 & 81,6 & B & $77,7 \varepsilon$ & 884,19 \\
\hline
\end{tabular}

$\overline{\mathrm{UU}}=$ ureia na urina, $\mathrm{NUU}=$ nitrogênio $(\mathrm{N})$ ureico na urina, $\mathrm{UP}=$ ureia no plasma, $\mathrm{NUP}=\mathrm{N}$ ureico no plasma; $\mathrm{A} \hat{\mathrm{Y}}=0,8235 * \mathrm{X}^{2}-11,9727 \mathrm{X}+174,6481$, B $\hat{Y}=0,3844 X^{2}-5,5881 X+81,5087 ; R^{2}=$ coeficiente de determinação, EPM $=$ Erro padrão da média.

Quadro 5. Teores de ácidos graxos de cadeia curta, nitrogênio amoniacal e potencial hidrogeniônico do conteúdo ruminal, coletado em diferentes tempos, de animais fistulados no rúmen, alimentados em função dos níveis da silagem da raiz de mandioca na dieta

\begin{tabular}{|c|c|c|c|c|c|c|}
\hline \multirow[t]{2}{*}{ SRM (\%) } & \multicolumn{6}{|c|}{ Itens } \\
\hline & Acético $^{1}$ & $\begin{array}{c}\text { Propiônico }^{2} \\
\mu \mathrm{mol} / \mathrm{mL}\end{array}$ & Butírico $^{3}$ & $\begin{array}{c}\text { Acético/ } \\
\text { Propiônico }\end{array}$ & $\begin{array}{c}\mathrm{N}-\mathrm{NH} 3^{5 \mathrm{~A}} \\
\mathrm{mg} / 100 \mathrm{~mL}\end{array}$ & $\mathrm{pH}^{6}$ \\
\hline 0 & 35,73 & 18,27 & 6,84 & 1,96 & 14,79 & 6,63 \\
\hline 3,62 & 36,28 & 17,71 & 6,24 & 2,05 & 13,81 & 6,62 \\
\hline 7,23 & 35,57 & 18,24 & 5,89 & 1,95 & 11,06 & 6,61 \\
\hline 10,84 & 36,79 & 16,98 & 8,05 & 2,17 & 15,51 & 6,58 \\
\hline 14,54 & 35,86 & 17,73 & 5,91 & 2,02 & 16,98 & 6,60 \\
\hline \multicolumn{7}{|l|}{$\mathrm{T}(\mathrm{h})$} \\
\hline 0 & 30,69 & 10,15 & 3,50 & 3,02 & 8,58 & 6,81 \\
\hline 2 & 39,07 & 23,28 & 8,92 & 1,68 & 23,34 & 6,55 \\
\hline 4 & 38,48 & 21,50 & 7,38 & 1,79 & 16,11 & 6,43 \\
\hline 6 & 40,10 & 21,33 & 7,91 & 1,88 & 12,90 & 6,59 \\
\hline 8 & \multicolumn{5}{|c|}{ Valor P } & 6,66 \\
\hline SRM & 0,9785 & 0,76 & 0,5704 & 0,9423 & 0,0010 & 0,4985 \\
\hline $\mathrm{T}$ & 0,0196 & $<0,0001$ & $<0,0001$ & $<0,0001$ & $<0,0001$ & $<0,0001$ \\
\hline \multirow[t]{2}{*}{ SRM*T } & 0,8101 & 0,8672 & $\begin{array}{r}0,3034 \\
\text { EPM }\end{array}$ & 0,6514 & 0,5674 & 0,9829 \\
\hline & 1,18 & 0,99 & 0,40 & 0,12 & 0,70 & 0,02 \\
\hline
\end{tabular}

N-NH3 = nitrogênio amoniacal, $\mathrm{pH}=$ potencial hidrogeniônico, $\mathrm{T}=$ tempo de coleta do conteúdo ruminal, SRM = nível de inclusão da silagem da raiz de mandioca na dieta. Equações: ${ }^{1} \mathrm{Y}=-0,5508 * \mathrm{t}^{2}+4,5742 * \mathrm{t}+$ $30,9961\left(R^{2}=89,98\right),{ }^{2} Y=-0,7571 * t^{2}+6,1892 * t+11,2614\left(R^{2}=89,98\right)$, ${ }^{3} \mathrm{Y}=-0,2563 * \mathrm{t}^{2}+2,1608 * \mathrm{t}+4,1310\left(\mathrm{R}^{2}=77,51\right),{ }^{4} \mathrm{Y}=0,0933 * \mathrm{t}^{2}-$ $0,8319 * t+3,5038\left(R^{2}=89,64\right),{ }^{5} Y=-0,5862 * t^{2}+4,3587 * t+10,9659$ $\left(\mathrm{R}^{2}=47,97\right),{ }^{6} \mathrm{Y}=0,0177 * \mathrm{t}^{2}-0,1551 * \mathrm{t}+6,8122\left(\mathrm{R}^{2}=87,96\right) ;{ }^{A} \mathrm{Y}=$ $0,0649 * m^{2}-0,7758 * m+14,9354\left(R^{2}=72,05\right)$, em que, $t=$ tempo $(h)$ e $\mathrm{m}=$ nível de inclusão da silagem da raiz de mandioca na dieta (\%), EPM = erro padrão da média.

Os teores de ácido acético, propiônico e butírico, além da relação acético/propiônico e o potencial hidrogeniônico $(\mathrm{pH})$, do conteúdo ruminal dos bovinos, não foram influenciados $(\mathrm{P}>0,05)$ pelos níveis de inclusão da silagem da raiz de mandioca na dieta total. Já o teor de nitrogênio amoniacal $\left(\mathrm{N}-\mathrm{NH}_{3}\right)$ apresentou comportamento quadrático, em função dos níveis de inclusão, obtendo-se o ponto mínimo $(12,62 \mathrm{mg} / 100 \mathrm{~mL}$ de conteúdo ruminal) no nível de 5,98\% (Quadro 5). 
Em função do tempo de coleta do conteúdo ruminal, os teores de ácido acético, propiônico e butírico, além da relação acético/propiônico, a concentração de $\mathrm{N}-\mathrm{NH}_{3}$ e o pH apresentaram comportamento quadrático. Ao derivar as equações obtidas para as variáveis citadas, estimaram-se os pontos máximo ou mínimo obtidos nos respectivos tempos de coleta do conteúdo ruminal. Os valores máximos estimados para os teores de ácido acético, propiônico e butírico $(40,49 ; 23,91$ e $8,69 \mu \mathrm{mol} / \mathrm{mL}$ de conteúdo ruminal, respectivamente) foram obtidos nos tempos 4,15; 4,09 e 4,22 horas (h) após o fornecimento da alimentação matutina. Já o maior valor para o $\mathrm{N}-\mathrm{NH}_{3}(19,07 \mathrm{mg} / 100 \mathrm{~mL})$ foi obtido 3,72 h após a alimentação. Por outro lado, para a relação acético/propiônico e para o pH foram encontrados os menores valores (1,65 e 6,47, respectivamente), obtidos 4,46 e 4,38 horas após a alimentação, respectivamente (Quadro 5).

\section{DISCUSSÃO}

O conhecimento sobre o metabolismo de compostos nitrogenados em bovinos é uma importante ferramenta na nutrição de ruminantes, pois uma redução no teor de nitrogênio (N) na urina, além de menores concentrações de ureia no plasma e/ou na urina, implicam em aumento na eficiência de utilização dos compostos nitrogenados, que estão diretamente relacionados às fontes de amido e de proteína bruta da dieta. Assim, deve haver uma relação ótima entre amido de rápida degradação ruminal e nitrogênio solúvel. Clark et al. (1992) sugeriram que quando a fermentação da matéria orgânica foi aumentada no rúmen, uma maior quantidade de proteína microbiana e uma menor quantidade de nitrogênio não amoniacal e não microbiano passaram para o intestino delgado.

$\mathrm{O}$ menor valor obtido para o consumo de $\mathrm{N}$ total $(142,14 \mathrm{~g} / \mathrm{dia})$ foi no nível de $5,82 \%$ de inclusão da silagem da raiz de mandioca, portanto, próximo à dieta com nível de inclusão de $7,23 \%$ de silagem da raiz da mandioca (Quadro 3). Entretanto, como o consumo de matéria seca foi semelhante em função dos níveis de inclusão, possivelmente, a variação na ingestão de $\mathrm{N}$ foi devido ao menor teor numérico de PB das dietas entre o nível de 3,62 e 7,23\% de inclusão de silagem de mandioca (Quadro 2).

Resultados semelhantes foram encontrados por Ouellet \& Chiquette (2016) que ao avaliarem dietas à base de silagem de trevo vermelho com e sem leveduras na alimentação de vacas, verificaram redução no consumo de $\mathrm{N}$ para as dietas que continham menores teores de PB. Sendo que as dietas com $168 \mathrm{~g} / \mathrm{kg}$ de $\mathrm{PB}$ proporcionaram consumo de $\mathrm{N}$ de 589,5 (g/dia), enquanto as que tinham 188,0 g/ $\mathrm{kg}$ de PB apresentaram consumo de $\mathrm{N}$ de 699,0g/dia.

$\mathrm{O}$ balanço de $\mathrm{N}$ apresentou comportamento linear crescente, o que mostra o efeito positivo da utilização da silagem da raiz de mandioca em dietas para bovinos alimentados com cana-de-açúcar aditivada com uma mistura de ureia + sulfato de amônio (10:1). Em todas as dietas experimentais não houve balanço de $\mathrm{N}$ negativo (Quadro 3), demonstrando que os requerimentos proteicos dos animais foram atendidos.

Silva et al. (2014), ao contrário deste estudo, não verificaram alteração no balanço de nitrogênio, ao incluir raiz de mandioca seca e triturada em até $72 \%$ no concentrado de vacas leiteiras mantidas em pastagem, apresentando média de 219 g/dia. Kljak et al. (2017) avaliando diferentes proporções de forragem e concentrado com dietas a base de silagem de sorgo, também não verificaram influencia sobre o balanço de $\mathrm{N}$ de novilhas.

Os valores médios de excreção de $\mathrm{N}$ na urina e nas fezes foram 22,45 e $42,40 \mathrm{~g} / \mathrm{dia}$, respectivamente. A semelhança entre as dietas para a excreção de $\mathrm{N}$ na urina e fezes, provavelmente, ocorreu devido à similaridade da digestibilidade da PB entre as dietas. As taxas de excreção de compostos nitrogenados na urina e nas fezes de ruminantes estão associadas com a quantidade de nitrogênio ingerido (Van Soest 1994), sendo assim, nesta pesquisa esperava-se uma menor excreção de $\mathrm{N}$ na urina próximo ao nível de 5,82\% de inclusão de silagem de mandioca, portanto, estatisticamente não foi encontrado, mas é importante relatar que foi verificada essa tendência, sendo que entre os níveis de 3,62 e 10,84\% de inclusão de mandioca, foram obtidas as menores médias numéricas para a excreções de $\mathrm{N}$ na urina (Quadro 3).

Mendonça et al. (2004), em estudo com vacas em lactação alimentadas com cana-de-açúcar, obtiveram valores médios para excreção de nitrogênio na urina e nas fezes de 104 e $117 \mathrm{~g} /$ dia, respectivamente. Os maiores valores de excreção de N obtidos por Mendonça et al. (2004) podem ser justificados pelo maior consumo de $\mathrm{N}$ total (383g/dia), em comparação ao atual estudo (150g/dia). Silva et al. (2014) também encontraram valores de excreção de nitrogênio pela urina $(81,04 \mathrm{~g} / \mathrm{dia})$ e pelas fezes $(97,20 \mathrm{~g} / \mathrm{dia})$ numericamente superiores aos obtidos neste estudo (Quadro 3); o consumo médio de nitrogênio encontrado por Silva et al. (2014) foi de 505,23g/dia. Entretanto, Conti et al. (2014) não encontraram diferenças significativas nas excreções de $\mathrm{N}$ pelas fezes, nem pela urina, quando vacas leiteiras, alimentadas com cana-de-açúcar, consumiram maiores quantidades de N (482 x 429g/dia). Animais mais produtivos devem consumir maiores quantidades de nitrogênio. Porém, este deve ser utilizado para a sua mantença e a sua produção, já que o seu excesso é eliminado, com gasto de energia, podendo também ser fonte de contaminação ambiental.

Em estudos envolvendo a utilização de compostos nitrogenados é relevante estimar a concentração e a excreção de ureia. Isto porque, com este parâmetro é possível avaliar a eficiência de utilização da energia e PB da dieta, sendo que quando a taxa de degradação de proteína excede a de carboidratos, grandes quantidades de nitrogênio podem ser perdidas, através da urina na forma de ureia.

Conti et al. (2014), apesar de não encontrarem diferenças significativas nas excreções de $\mathrm{N}$ pelas fezes ou pela urina de vacas leiteiras, obtiveram maior concentração de ureia plasmática nos animais alimentados com dieta contendo maior teor de proteína bruta $(15,6 \%)$, em detrimento da dieta com menor teor $(14,2 \%)$.

As concentrações de ureia e de nitrogênio ureico na urina e no plasma não diferiram entre as dietas $(P>0,05)$, sendo um indicativo do potencial da silagem da raiz de mandioca como alternativa ao milho grão na dieta de bovinos. 
0 valor médio de ureia no plasma dos bovinos foi $31,43 \mathrm{mg} /$ dL (Quadro 4). Mendonça et al. (2004) obtiveram o valor médio de $51 \mathrm{mg} / \mathrm{dL}$ de ureia no plasma de vacas leiteiras recebendo $60 \%$ de cana-de-açúcar na dieta; valor acima do obtido no presente estudo. Menor teor de ureia no plasma indica menores perdas de proteína, ingrediente de maior custo na dieta de bovinos. Ao contrário do atual estudo, Pires et al. (2008) verificaram alteração significativa para o teor de ureia plasmática (médias de 21,9; 23,6; 21,3; 21,4 e $27,6 \mathrm{mg} / \mathrm{dL}$ ) em vacas leiteiras alimentadas com milho moído grosso, milho moído fino, milho floculado $310 \mathrm{~g} / \mathrm{L}$, milho floculado $360 \mathrm{~g} / \mathrm{L}$ e raspa de mandioca $(28,4 \%$ da dieta total), respectivamente.

$\mathrm{O}$ valor de $\mathrm{N}$-ureico no plasma obtido no atual ensaio foi de $14,67 \mathrm{mg} / \mathrm{dL}$ (Quadro 4). Resultados superiores foram obtidos por Zambom et al. (2015) que obtiveram média de $19,9 \mathrm{mg} / \mathrm{dL}$ de $\mathrm{N}$-ureico no plasma de vacas Holandesas alimentadas com silagem do resíduo da extração do amido de mandioca, substituindo $0 \%, 25 \%, 50 \%, 75 \%$ ou $100 \%$ do milho da ração. A menor média encontrada no presente trabalho, possivelmente, foi devido ao menor teor médio de PB das dietas (13,5\%) (Quadro 2) quando comparada a concentração de PB $(16,1 \%)$ das rações da pesquisa de Zambom et al. (2015).

De acordo com Oliveira et al. (2001), concentrações de nitrogênio ureico no plasma de 19 a $20 \mathrm{mg} / \mathrm{dL}$ representam os limites a partir dos quais estariam ocorrendo perdas de nitrogênio dietético em vacas leiteiras. Silva et al. (2014) não obtiveram diferenças significativas para o $\mathrm{N}$-ureico na urina e no plasma, ao adicionar até $72 \%$ de raiz de mandioca seca e triturada no concentrado para vacas em lactação mantidas em pastagens tropical. Oliveira et al. (2007) obtiveram médias de $13,03 \mathrm{mg} / \mathrm{dL}$ para $\mathrm{N}$-ureico no plasma de vacas em lactação alimentadas com $40 \%$ de cana-de-açúcar e $60 \%$ de concentrado. Já Mendonça et al. (2004) obtiveram médias de $24 \mathrm{mg} / \mathrm{dL}$ de $\mathrm{N}$-ureico no plasma de vacas leiteiras recebendo $60 \%$ de cana-de-açúcar na dieta.

A ausência de efeito significativo nas concentrações de $\mathrm{N}$-ureico na urina e no plasma sugere que o nitrogênio dietético e a amônia produzida na fermentação ruminal das dietas foram usados de maneira semelhante pelos animais. Quando há excesso de nitrogênio dietético não utilizado pelos microrganismos, estes o convertem em amônia, que, absorvida pelo epitélio ruminal, é excretada pelos rins na forma de ureia ou reciclada para o rúmen por intermédio da saliva ou da parede ruminal (Pereira et al. 2005). Os menores valores para excreção de ureia $(131,13 \mathrm{~g} / \mathrm{dia})$ e de $\mathrm{N}$ -ureico $(61,20 \mathrm{~g} / \mathrm{dia})$ pela urina, obtidos no nível de $7,27 \%$, podem ser explicados pelo comportamento do consumo de $\mathrm{N}$ total, que teve seu ponto de mínimo no nível de 5,82\% de silagem da raiz de mandioca na dieta.

Os ácidos graxos de cadeia curta (Quadro 5) não foram influenciados $(\mathrm{P}>0,05)$ pelos níveis de inclusão da silagem da raiz da mandioca. Silveira et al. (2002) obtiveram valores semelhantes para os ácidos acético, propiônico e butírico, e a relação acético: propiônico, quando forneceram aos bovinos silagens de milho, de raspa de mandioca com polpa cítrica ou de casca de mandioca com polpa cítrica. A proporção entre os ácidos acético, propiônico e butírico manteve-se dentro dos níveis esperados (60:29:11). De acordo com Nussio et al. (2006), dietas à base de volumoso apresentam proporções geralmente próximas a 65:25:10 de acetato:propionato:butirato. Silveira et al. (2009) obtiveram uma proporção de 67:26:7 para acetato: proprionato: butirato em bovinos alimentados com cana-de-açúcar. Os picos de produção dos ácidos graxos de cadeia curta foram obtidos, aproximadamente, 4 horas após o fornecimento da alimentação.

Outro parâmetro para verificar se a dieta fornecida estaria adequada às características fisiológicas do ruminante é a concentração de nitrogênio amoniacal $\left(\mathrm{N}-\mathrm{NH}_{3}\right)$ ruminal (Silveira et al. 2009). Nas mais variadas situações, 40 a $100 \%$ do nitrogênio exigido pelos microrganismos poderia ser derivado do nitrogênio amoniacal (Stern \& Hoover 1979). 0 menor valor de $\mathrm{N}-\mathrm{NH}_{3}(12,62 \mathrm{mg} / 100 \mathrm{~mL})$, obtido no nível de 5,98\% de inclusão da silagem da raiz de mandioca, foi suficiente para garantir o crescimento bacteriano, conforme Preston (1986), que citou o valor de $5 \mathrm{mg}$ de N$-\mathrm{NH}_{3} / 100 \mathrm{~mL}$ de conteúdo ruminal como mínimo para garantir o crescimento de bactérias. $\mathrm{O}$ menor valor de $\mathrm{N}-\mathrm{NH}_{3}$ $(12,62 \mathrm{mg} / 100 \mathrm{~mL})$, obtido no nível de $5,98 \%$, pode ser justificado pelo consumo de $\mathrm{N}$ total, que foi menor em nível de inclusão semelhante $(5,82 \%)$. Dessa forma, o consumo de $\mathrm{N}$ total poderia ser relacionado à concentração de $\mathrm{N}-\mathrm{NH}_{3}$ no conteúdo ruminal dos bovinos.

Fregadolli et al. (2001) não observaram modificações nas concentrações de $\mathrm{N}-\mathrm{NH}_{3}$ no conteúdo ruminal de bovinos alimentados com milho ou casca de mandioca, obtendo valor médio de $8,46 \mathrm{mg} / 100 \mathrm{~mL}$ de conteúdo ruminal. Para otimizar a taxa de desaparecimento da celulose e da fibra dos alimentos incubados em sacos de náilon no rúmen, bons resultados foram observados quando a concentração de nitrogênio amoniacal ruminal foi elevada para $20 \mathrm{mg}$ $\mathrm{N}-\mathrm{NH}_{3} / 100 \mathrm{~mL}$ (Silveira et al. 2002). Neste estudo, dentre os valores médios obtidos nas diferentes dietas, o maior $(16,98 \mathrm{mg} / 100 \mathrm{~mL})$ foi obtido na dieta com nível de inclusão de $14,54 \%$ de silagem da raiz de mandioca.

Carboidratos não fibrosos, de rápida degradação ruminal, como o amido da mandioca, podem provocar redução no $\mathrm{pH}$ do rúmen, interferindo na biohidrogenação ruminal, mas isso não aconteceu no presente estudo (Quadro 5). Os valores de $\mathrm{pH}$ ruminal não modificaram $(\mathrm{P}>0,05)$ com a inclusão da silagem da raiz da mandioca na dieta, apresentando média de 6,61. De acordo com Coelho \& Leão (1979), valores de $\mathrm{pH}$ inferiores a 6,0 podem acarretar diminuição da atividade das bactérias fibrolíticas, reduzindo a degradação da fibra.

Fregadolli et al. (2001), avaliando o efeito de dietas contendo fontes de amido de alta (casca de mandioca) e baixa (milho) degradabilidade ruminal, com fontes de $\mathrm{N}$ de alta (levedura) e baixa (farelo de algodão e farinha de carne e ossos) degradabilidade ruminal, não observaram alterações significativas no $\mathrm{pH}$ ruminal de bovinos. Não foram observadas mudanças significativas no $\mathrm{pH}$ do conteúdo ruminal de bovinos alimentados com silagens de milho, de raspa de mandioca com polpa cítrica ou de casca de mandioca com polpa cítrica (Silveira et al. 2002). Com relação ao pH nos diferentes tempos de coleta do conteúdo ruminal, Frega- 
dolli et al. (2001) obtiveram o menor valor $(6,20)$ 4,6 horas após a alimentação, enquanto no atual estudo o menor valor $(6,47)$ foi obtido 4,38 horas após o fornecimento das dietas (Quadro 5). 0 menor valor de $\mathrm{pH}$ encontrado por esses autores $(6,20)$, em detrimento do presente estudo $(6,47)$, se deve ao fato de terem trabalhado com uma relação volumoso: concentrado maior (50:50), enquanto neste estudo essa relação foi de 73:27. Maeda et al. (2007), obtiveram o valor mínimo de $\mathrm{pH}(6,30)$, no conteúdo ruminal de bovinos, 4,40 horas após o fornecimento da alimentação, ao avaliarem a influência do fornecimento de 23,43 e $63 \%$ de concentrado, sendo o milho moído e o resíduo desidratado de fécula de mandioca as fontes de amido.

\section{CONCLUSÕES}

O nível de 7,23\% de silagem da raiz de mandioca na dieta é mais eficiente na utilização dos compostos nitrogenados.

O milho moído e a silagem da raiz de mandioca contribuem de forma semelhante para a produção dos ácidos graxos de cadeia curta, sem interferir no $\mathrm{pH}$ ruminal.

Os valores de $\mathrm{N}-\mathrm{NH}_{3}$ ruminal foram suficientes para garantir o crescimento microbiano, independentemente das dietas experimentais.

Agradecimentos.- Ao CNPq, Embrapa, FAPESB, UESC, INCT em Ciência Animal pela parceria e apoio financeiro à pesquisa.

\section{REFERÊNCIAS}

Argov-Argaman N., Eshel O., Moallem U., Lehrer H., Uni Z. \& Arieli A. 2012. Effects of dietary carbohydrates on rumen epithelial metabolism of nonlactating heifers. J. Dairy Sci. 95(7):3977-3986.

Broderick G.A. \& Clayton M.K. 1997. A statistical evaluation of animal and nutritional factors influencing concentrations of milk urea nitrogen. J. Dairy Sci. 80(11):2964-2971.

Clark J.H., Klusmeyer T.H. \& Cameron M.R. 1992. Microbial protein synthesis and flows of nitrogen fractions to the duodenum of dairy cows. J. Dairy Sci. 75(8):2304-2323.

Coelho J.F.S. \& Leão M.I. 1979. Fundamentos de nutrição de ruminantes. Ceres, Piracicaba. 380p.

Conti L.H.A., Jesus E.F., Pereira A.S.C., Arcari M.A., Peixoto Júnior K.C., Rennó F.P. \& Santos M.V. 2014. Nitrogen balance and milk composition of dairy cows fed with urea and soybean meal and two protein levels using sugar cane based diets. Braz. J. Vet. Res. Anim. Sci. 51(3):242-251.

Detmann E., Souza M.A. \& Valadares Filho S.C. 2012. Métodos para Análise de Alimentos. Suprema, Viçosa. 214p.

FAO 2014. Food Outlook: biannual report on global food markets. Disponível em <http://www.fao.org/3/a-i4136e.pdf> Acesso em Dez 2, 2015.

Fenner F. \& Ratcliffe F.N. 1965. Myxomatosis. Cambridge University Press, London. 379p.

Fregadolli F.L., Zeoula L.M., Branco A.F., Prado I.N., Caldas Neto S.F., Guimarães K.C., Kassies M.P. \& Dalponte A.O. 2001. Efeito das fontes de amido e nitrogênio de diferentes degradabilidades ruminais. 2. pH, concentração de amônia no líquido ruminal e eficiência de síntese microbiana. Revta Bras. Zootec. 30(3):870-879.

Hall M.B. \& Akinyode A. 2000. Cottonseed hulls: working with a novel fiber source. Proc. Annual Florida Ruminant Nutrition Symposium, Gainesville, 11:179-186.

Kljak K., Pino F. \& Heinrichs A.J. 2017. Effect of forage to concentrate ratio with sorghum silage as a source of forage on rumen fermentation, $\mathrm{N}$ balance, and purine derivative excretion in limit-fed dairy heifers. J. Dairy Sci. 100:213-223.

Maeda E.M., Zeoula L.M., Geron L.J.V., Best J., Prado I.N., Martins E.N. \& Ka- zama R. 2007. Digestibilidade e características ruminais de dietas com diferentes níveis de concentrado para bubalinos e bovinos. R. Bras. Zootec. 36(3):716-726.

Mendonça S.S., Campos J.M.S., Valadares Filho S.C., Valadares R.F.D., Soares C.A., Lana R.P., Queiroz A.C., Assis A.J. \& Pereira M.L.A. 2004. Balanço de compostos nitrogenados, produção de proteína microbiana e concentração plasmática de ureia em vacas leiteiras alimentadas com dietas à base de cana-de-açúcar. Revta Bras. Zootec. 33(2):493-503.

NRC 2001. Nutrients requirements of dairy cattle. 7th ed. National Academy Press, Washington, DC. 381p.

Nussio L.G., Campos F.P. \& Lima M.L.M. 2006. Metabolismo de carboidratos estruturais. In: Berchielli T.T., Pires A.V. \& Oliveira S.G. (Eds). Nutrição de ruminantes. Funep, Jaboticabal, p.183-228.

Oliveira A.S., Campos J.M.S., Valadares Filho S.C., Assis A.J., Teixeira R.M.A., Rennó L.N., Pina D.S. \& Oliveira G.S. 2007. Substituição do milho pela casca de café ou de soja em dietas para vacas leiteiras: comportamento ingestivo, concentração de nitrogênio ureico no plasma e no leite, balanço de compostos nitrogenados e produção de proteína microbiana. Revta Bras. Zootec. 36(1):205-215.

Oliveira A.S., Valadares R.F.D., Valadares Filho S.C., Cecon P.R., Rennó L.N., Queiroz A.C. \& Chizzotti M.L. 2001. Produção de proteína microbiana e estimativas das excreções de derivados de purinas e de uréia em vacas lactantes alimentadas com rações isoprotéicas contendo diferentes níveis de compostos nitrogenados não-protéicos. Revta Bras. Zootec. 30(5):1621-1629.

Ouellet D.R. \& Chiquette J. 2016. Effect of dietary metabolizable protein level and live yeasts on ruminal fermentation and nitrogen utilization in lactating dairy cows on a high red clover silage diet. Anim. Feed Sci. Technol. 220:73-82.

Pereira E.S., Arruda A.M.V., Miranda L.F., Mizubuti I.Y., Muniz E.B. \& Pinto A.P. 2005. Importância da inter-relação carboidrato e proteína em dietas de ruminantes. Semina, Ciênc. Agrárias 26(1):125-134.

Pires A.V., Susin I., Santos F.A.P., Mendes C.Q., Oliveira Junior R.C., Fernandes J.J.R. \& Simas J.M.C. 2008. Efeito de fontes e formas de processamento do amido sobre o desempenho e o metabolismo do nitrogênio em vacas Holandesas em lactação. Revta Bras. Zootec. 37(8):14561462.

Preston T.R. 1986. Analytical methods for characterizing In: Feed resources for ruminants. Better utilization of crop residues and by products in animal feeding: research guidelines. 2. A practical manual for research workers. FAO, Rome. 106p.

Rangel A.H.N., Leonel F.P., Braga A.P., Pinheiro M.J.P. \& Lima Júnior D.M. 2008. Utilização da mandioca na alimentação de ruminantes. Revta Verde Agroecologia Desenvolv. Sustent. 3(2):1-12.

Silva A.C., Figueiredo M.P., Bonomo P., Pereira M.L.A., Luz Y.S. \& Santos E.J. 2014. Microbial protein synthesis and nitrogen metabolism in cows bred on tropical pasture and fed on cassava root and corn. Acta Scient. Anim. Sci. 36(2):185-19.

Silveira R.N., Berchielli T.T., Canesin R.C., Messana J.D., Fernandes J.J.R. \& Pires A.V. 2009. Influência do nitrogênio degradável no rúmen sobre a degradabilidade in situ, os parâmetros ruminais e a eficiência de síntese microbiana em novilhos alimentados com cana-de-açúcar. Revta Bras. Zootec. 38(3):570-579.

Silveira R.N., Berchielli T.T., Freitas D., Salman A.K.D., Andrade P., Pires A.V. \& Fernandes J.J.R. 2002. Fermentação e degradabilidade ruminal em bovinos alimentados com resíduos de mandioca e cana-de-açúcar ensilados com polpa cítrica peletizada. Revta Bras. Zootec. 31(2):793801.

Simas J.M.C., Pires A.V., Susin I., Santos F.A.P., Mendes C.Q., Oliveira Júnior R.C. \& Fernandes J.J.R. 2008. Efeitos de fontes e formas de processamento do amido na utilização de nutrientes e parâmetros ruminais de vacas em lactação. Arq. Bras. Med. Vet. Zootec. 60(5):1128-1134.

Sniffen C.J., O'connor D.J., Van Soest P.J., Fox D.G. \& Russell J.B. 1992. A net carbohydrate and protein system for evaluating cattle diets: carbohydrate and protein availability. J. Anim. Sci. 70(12):3562-3577.

Stern M.D. \& Hoover W.H. 1979. Methods for determining and factors 
affecting rumen microbial protein syntheses: a review. J. Anim. Sci. 49(5):1590-1603.

Valadares R.F.D., Broderick G.A., Valadares Filho S.C. \& Clayton M.K. 1999. Effect of replacing alfalfa silage with high moisture corn on ruminal protein synthesis estimated from excretion of total purine derivatives. J. Dairy Sci. 8:2686-2696.

Van Soest P.J. 1994. Nutritional ecology of the ruminant. 2nd ed. Cornell University Press, Ithaca.

Vieira P.F. 1980. Efeito do formaldeído na proteção de proteínas e lipídeos em rações. Tese de Doutorado em Zootecnia. Disponível em <//http:www.ufv.br//> Acesso em 18 abr. 2014.

Weiss W.P. 1999. Energy prediction equations for ruminant feeds. Proc. 61th Cornell Nutrition Conference for Feed Manufacturers, p.176185.

Zambom M.A., Fernandes T., Schmidt E.L., Gonçalves J.A.G., Pozza M.S.S., Javorski C.R., Souza L.C. \& Tinini R.C.R. 2015. Silage of residue from the extraction of cassava starch in diets from lactating holstein cows. Semina, Ciênc. Agrárias 36(3):1701-1712. 